\title{
UNA APROXIMACIÓN A LA GÉNESIS DE LAS \\ POTENCIAS DE LO FALSO EN GILLES DELEUZE
}

\author{
AN APPROACH TO THE GENESIS OF THE \\ POWER OF THE FALSE IN GILLES DELEUZE
}

\author{
Sergio MarTínez V. \\ Universidad de Chile
}

\begin{abstract}
Resumen: En el presente trabajo nos aproximaremos a Gilles Deleuze problematizando lo que él llama potencias de lo falso. Para desarrollar esto, buscaremos relacionar aquellas potencias con lo que el filósofo francés denomina caos-cosmos. En principio, consideraremos, como una guía para sostener aquella relación, la inversión del platonismo propuesta por Deleuze. Pues bien, quizá el problema que presentan las potencias de lo falso es el de la verdad en tanto producción. Será en este último sentido que sostendremos que se encontraría la verdad de lo falso en la relación entre arte y pensamiento.
\end{abstract}

Palabras Claves: potencias de lo falso, caos-cosmos, inversión del platonismo, arte, pensamiento.

АвsтRACT: In this work we approach G. Deleuze, problematizing the powers of the false. In principle, the issue at stake in this proposal is the inversion of Platonism. And to explore this power, it is necessary to expose what Deleuze denominated caos-cosmos. Perhaps this will allow us to conceive that the issue of the power of the false is the issue of the production of truth. In this last sense, we will consider that the true of the false can be found in the relation between art and thought.

KeYwords: powers of the false, caos-cosmos, inversion of Platonism, art, philosophy.

\footnotetext{
* Investigador asociado Facultad de Artes. Universidad de Chile. Las Encinas №3370, Macul, Santiago - Chile. Doctor en Filosofía. Mención en Estética y Teoría del Arte. Becario Conicyt 2013-2017. Universidad de Chile. E-mail: sergiosermar@ug.uchile.cl
} 
G.Deleuze.- No sería ese Platón. Si pensamos en el Platón de la última dialéctica,

en donde las Ideas son casi como multiplicidades que han de recorrerse mediante las preguntas

¿cómo? ¡cuándo? ¿en qué caso?, entonces, sí, todo lo que digo me parece, en efecto, platónico.

Si se trata, al contrario, del Platón, partidario de una simplicidad de la esencia o de una ipseidad de la Idea, entonces no.

El método de dramatización

$[\mathrm{L}]$ a potencia de lo falso es inseparable de una irreductible multiplicidad.

«Yo es otro [Je est un autre]» ha reemplazado a Yo= Yo [Moi = Moi].

La imagen-tiempo

\section{Introducción}

En este trabajo buscaremos exponer cuál es la naturaleza de las potencias de lo falso a través de una lectura de Diferencia y repetición de Gilles Deleuze. Pero no restringiremos la interpretación que propondremos a aquella obra, más bien la consideraremos como una guía que quizás nos permita ir más allá de ella. En esta obra Deleuze volverá a proponer una lectura de F. Nietzsche para buscar exponer la naturaleza de aquellas potencias. ${ }^{1}$ Según el filósofo francés, Nietzsche no es solo el pensador de la voluntad de poder o del eterno retorno (o del Übermensch o del nihilismo), más bien estos conceptos son los que se le presentan al filósofo alemán como necesarios para considerar que la naturaleza de la verdad la expresa las potencias de lo falso. Para decirlo de otro modo, para Deleuze la naturaleza de la natura naturans la expone la naturaleza de lo falso; recordemos que Nietzsche afirmó haber encontrado un precedente en

1 Recordemos que la primera interpretación que Deleuze propone de Nietzsche se halla en un libro cuyo título sintetiza el valor que le da Deleuze al pensamiento de Nietzsche al considerar en términos nietzscheanos que la relación que está en juego podría leerse como una antítesis, Nietzsche y la filosofía. 
Spinoza (Nietzsche, 1999: 168). Ahora bien, la verdad que aquella naturaleza expresa se presenta en tanto problema en la medida en que las potencias de lo falso se relacionarían con lo que Deleuze llama caos-cosmos. Es esta nuestra hipótesis, y para desplegarla consideraremos a modo de segunda hipótesis que aquella relación se descubriría en la relación entre arte y pensamiento. En este sentido, las lecturas que realiza Deleuze de diversas obras de arte, y que nutren su propuesta filosófica, ${ }^{2}$ estarían íntimamente relacionadas con la exploración de aquella relación.

Este trabajo lo dividiremos en cuatro partes. En la primera parte, titulada: la operación de la defundamentación, proponemos una aproximación a lo que en Diferencia y repetición se denomina la inversión del platonismo, extrayendo las consecuencias que implica esta inversión para el despliegue de nuestra hipótesis. En la segunda parte, titulada: ¿quién piensa en el pensamiento?, expondremos la lectura que propone Deleuze de la introducción de la forma vacía del tiempo en el pensamiento. Consideramos que ésta es fundamental para ahondar en nuestra hipótesis en cuanto es la experiencia que hace el pensamiento bajo aquella forma la que expondría radicalmente las consecuencias de aquella operación. En este sentido, en la tercera parte, titulada: el arte de la caverna, volveremos nuevamente a la lectura de Deleuze de Platón, ahora considerando la posibilidad de expresar con aquella lectura la relación entre las potencias de lo falso y el caos-cosmos. Finalmente, en la cuarta parte, titulada: el círculo y la linea, buscaremos presentar la relación entre arte y pensamiento ateniendo, en tono nietzscheano, que el arte es la expresión más alta de las potencias de lo falso: "santifica la mentira, hace de la voluntad de engañar un ideal superior" (Deleuze, 2002: 145). Pues, "no hay sino devenir, y el devenir es la potencia de lo falso de la vida, la voluntad de potencia" (Deleuze, 2015: 191).

\footnotetext{
2 Afirmar esto implica divergir de las lecturas que enfatizan la relación de Deleuze con las ciencias. Al respecto, ejemplarmente por el vínculo que establece con la física post-newtoniana, M. de Beistegui (2004) Pero, sin desconocer esto, habríamos de considerar el contenido ficcional del uso que hace Deleuze de las ciencias, pues él mismo dice, citamos, prefacio a Diferencia y repetición, "[U]n libro de filosofía debe ser, por un lado, una especie muy particular de novela policial, y por otro lado, una suerte de ciencia ficción. (...). Hemos hablado de ciencia en una forma que, bien lo sentimos, por desdicha no es científica" (2012:17-18). Aquí creemos que habría que desarrollar una suerte de diagnóstico que nos llevaría a investigar por el sentido del humor deleuzeano. Por supuesto, esto sería asunto de otro trabajo.
} 


\section{La operación de la defundamentación}

Para Deleuze, como lo expresará en Diferencia y repetición, la tarea de la filosofía moderna no será otra que la inversión (renversement) del platonismo (2012: 105). ${ }^{3}$ Pero el derrocamiento de aquella tradición es complejo en cuanto implica conservar algunas características del derrocado. Principalmente, como veremos, para Deleuze se tratará de extraer lo que se podría llamar el fundamento infundado del platonismo. Esto es, hay que conservar del platonismo aquello que resiste la mediación de una identidad conceptual y que al tiempo "es objeto de un encuentro fundamental" (2012: 215). Es esta resistencia que expresa el objeto de un encuentro lo que obliga al pensamiento a sentir y pensar, lo cual al mismo tiempo exige plantear de otro modo la pregunta por la naturaleza del pensamiento en tanto la exigencia adviene del afuera de él (volveremos a esto). Para Deleuze, en los diálogos llamados aporéticos Platón hace uso de la pregunta "¿qué es?" con un fin propedéutico, ya que si esta pregunta conduce a la contradicción y desemboca en el nihilismo es porque ella conlleva aquella dirección. Como expondrá Deleuze, si aquella pregunta deja lugar a otras preguntas de otro modo eficaces y potentes es porque con la misma forma de la pregunta Platón busca abrir la región de un problema en el que las ideas no pueden concebirse como idénticas a sí, esto es, ellas están más allá del primado del principio de identidad (o de una estabilidad estática del sentido) (2012: 285). Respecto a este punto, hay que volver a decir que el derrocamiento del platonismo es más complejo de lo que a simple vista podría creerse, porque la aporía no deja de ser un medio de acceso a aquella región. ${ }^{4}$ Pero no podemos caracterizar el pensamiento de Deleuze como aporético, como ha señalado F. Zourabichvilli, a Deleuze le interesa desarrollar una lógica de lo irracional, "una lógica extrema y sin racionalidad" (2007: 103). ${ }^{5}$ Y la relación entre las potencias de lo falso y el caos-cosmos implica un despliegue de aquella lógica en tanto sostiene su necesidad desde afuera. Pues bien, dirá Deleuze respecto a Platón, en cuanto "se trata de poner en movimiento la dialéctica, la pregunta

\footnotetext{
3 Quienes han explorado desde una vertiente histórica y genealógica la inversión platónica propuesta por Deleuze, son Daniel. W. Smith (2012) y Miguel de Beistegui (2012).

4 Estaríamos tentados a preguntar, ¿el platón místico? pero quizás Nietzsche exclamaría o sonreiría, ¿uun Platón dionisiaco?

5 "Irracional: la palabra no puede dar miedo, o justificar amalgamas lastimosas, sino desde el punto de vista de una nostalgia del racionalismo, vale decir, de un pensamiento que no habría recorrido el círculo del fundamento y no se hubiese convencido de no sostener su necesidad sino desde afuera, vale decir, de un encuentro con lo que lo obliga a pensar" (Zourabichvili, 2007: 88).
} 
¿qué es? [cursivas de G.D] deja lugar a otras preguntas, de otro modo eficaces y poderosas (efficaces et puissantes), de otro modo imperativas: ¿cuánto, cómo, en qué caso? [cursivas nuestras]" (2012: 285). Tenemos, por un lado, que considerar que para Deleuze un método plantea preguntas y una ontología problemas, y constantemente estas remiten unas a otras; por otro lado, lo que se aprende de una Idea se descubre en un encuentro con ella. Lo primero puede de otro modo plantearse considerando lo que dirá Deleuze a propósito de Bergson, "diferencias de naturaleza y naturaleza de la diferencia (...), [no] aparecen [sino] ligados" (2005: 45). Esto es, tienen que proponerse otros procedimientos para explorar la naturaleza de una idea que es la de la diferencia en tanto los procedimientos se generan en base a otra experiencia de ella, pues tenemos que considerar que lo que Deleuze busca expresar bajo aquella ligazón es: que las diferencias de naturaleza son inmanentes a la naturaleza de la diferencia en tanto aquellas preguntas implícitamente expresan que tiene que explorarse la idea de la diferencia como si se tratase de un campo que solo se recorriese planteando otros procedimientos que permitan llevar a cabo el recorrido. ${ }^{6}$ ¿Qué quiere decir esto, en cuanto buscamos concebir aquella ligazón, si solo se aprende la naturaleza de una idea en un encuentro con ella? Es ahora cuando tendremos que considerarla bajo la operación de la "defundamentación universal (effondement universal)" (Deleuze, 2012: 116), pues en ella la inversión, creemos, comienza a tornarse relevante: ahí un encuentro comienza a modularse. Para Deleuze, la defundamentación en cuanto operación nunca termina por expresar: "esa libertad del fondo no mediatizada, este descubrimiento de un fondo detrás de cualquier otro fondo, esa relación de lo sin-fondo con lo no-fundado" (2012: 116). Ahora bien, para aprehender aquella operación y aquella ligazón, en cuanto en el proceder del defondamiento se confunde lo sin-fondo con lo no-fundado, será necesario distinguir la naturaleza de la diferencia de la del tiempo (Deleuze, 2012: 116). Aquella operación implicada en la inversión del platonismo no sólo expresa que la diferencia se concibe en el tiempo, sino también, dicho bergsonianamente, que la idea de diferencia es la de la duración en tanto que multiplicidad intensiva. ${ }^{7}$ En otras palabras, para Deleuze implica tiempo la diferencia y la desenvoltura de

\footnotetext{
6 La noción de campo Deleuze la introduce con fuerza en Lógica del sentido, serie $X V$, en referencia a los trabajos de Gilbert Simondon. Quien ha notablemente enfatizado el papel que cumple Simondon en el pensamiento de Deleuze, es A. Sauvagnargues (2009), especialmente en los capítulos X y XI y la primera parte del XII.

7 H. Bergson, retroactivamente leído por Deleuze (2005), concebía desde una perspectiva ontológica que la idea de multiplicidad podríamos considerarla actual (extensiva) y virtualmente (intensivamente). Ver también el fundamental capítulo "De la multiplicidad de los estados de conciencia" de Ensayo sobre los datos inmediatos de la conciencia (1999).
} 
la diferencia en el tiempo se la explora considerando otros procedimientos, otras preguntas, que permitan concebir el movimiento que en el tiempo expresa ella. Pero podría replicarse: Deleuze busca exponer que la naturaleza de la diferencia es la del acontecimiento y para pensar en él hay que concebirlo en tanto relación; en Deleuze, debe ser pensada la idea de diferencia bajo el concepto de relación en la medida en que aquellas preguntas recorren el campo de un problema que lo diferencia una multiplicidad de relaciones (por ejemplo, en el libro Prousty los signos la figura de la araña es la que se torna relevante en tanto despliega las intensidades en las que consiste aquella obra, este es el personaje conceptual de aquel libro como autor anónimo de las relaciones que se tejen en la recherche de Proust). Pues bien: Deleuze afirma que "las Ideas son multiplicidades puras" (2012: 293), pero dirá también que, citamos,

el dominio de la Idea es el de lo inesencial. La Idea se declara de parte de lo inesencial de una manera tan resuelta, con tan cruel obstinación, como aquella con la que el racionalismo declaraba, por el contrario, para la Idea, la posesión y la comprensión de la esencia” (2012: 284).

Si aquellas preguntas expresan que la naturaleza de la Idea es la de lo inesencial en tanto en cuanto ella implica el tiempo, será la inversión planteada por Deleuze la que comenzará a cobrar otros tintes. Pues aquellos procedimientos bajo otra coloratura expresan que es la diferencia en tanto Idea: una multiplicidad que cambia de naturaleza en la medida en que se diferencia: una heterogeneidad cuya duración es distintiva de ella. Como dirá Deleuze, si "el problema, como objeto de la Idea, se encuentra del lado de los sucesos, de los accidentes, de las afecciones" (2012: 284), lo que sea una idea de diferencia lo aprenderemos en el tiempo en cuanto se expresan en él los sucesos, los accidentes, las afecciones, que presentan las diferencias de naturaleza que están ligadas inmanentemente a la naturaleza de la diferencia. Por ello, es la naturaleza de la diferencia la de la pura contingencia. Ahora bien, para considerar estos cambios es necesario

En este sentido, el tiempo de la diferencia sería el de una heterogeneidad indivisible, simbólicamente no-reductible (volveremos a esto). Y acaso, ¿no se trata sino de la Memoria? Para considerar el paso de la psicología, de la epistemología y de la ontología bergsoniana, concibiendo un continuo hecho de rupturas entre multiplicidades, ver, M. Ruiz Stull (2013). 
algo que nos lo hagan sensibles y pensables, algo que vuelva a traer un acontecimiento, algo que componga un acontecimiento. ¿Cómo se presenta aquello que persiste?, ¿cómo podemos sentir y pensar en la diferencia?, ¿cuál encuentro con la diferencia? En efecto, no en vano se ha llamado a la propuesta deleuzeana, partiendo por el mismo Deleuze, empirismo trascendental. Y podríamos decir que para Deleuze "la obra de arte que abandona el dominio de la representación para devenir "experiencia», empirismo trascendental o ciencia de lo sensible" (2012: 101), es el objeto poético a sentir y pensar. ${ }^{8}$ Es un objeto poético el que vuelve a dar la diferencia o, más bien, en tanto objeto de experimentación, él crea una diferencia que nos la hace sensible y pensable.

En la relación entre arte y pensamiento hallaríamos una expresión de la diferencia en tanto ella se experimenta en una obra de arte. ${ }^{9}$ Es decir, si consideramos que la relación entre las potencias de lo falso y el caos-cosmos la presenta aquella relación, en ella es una experiencia de lo real lo que se expresa. Pero para desarrollar esto, será necesario antes preguntar: ¿cuál es la experiencia del pensamiento que está considerando Deleuze? Ello, creemos, nos permitirá preguntar por la relación entre aquellas potencias y el caos-cosmos en cuanto no deja de insistir la pregunta por las condiciones de aquella experiencia.

\section{3. ¿Quién piensa en el pensamiento?}

En Deleuze, lo que hace interesante la naturaleza de la diferencia es lo que la torna problemática, y nuestra hipótesis es que la relación entre el caos-cosmos y las potencias de lo falso hace de aquella naturaleza un problema. Pues bien, para Deleuze la experiencia del pensamiento se produce en y por un encuentro que resquebraja la naturaleza de la representación (2012: 101), ahora al mismo tiempo tenemos que concebir que lo que distingue aquella experiencia de la naturaleza de la representación es que el tiempo se ha introducido en aquella experiencia. Es decir, en cuanto lo que hace pensar se halla en la relación entre lo no-fundado y lo sin-fondo, es necesario considerar el proceder del defondamiento en el tiempo para concebir la experiencia del pensamiento. En este

\footnotetext{
8 Tomamos la noción de objeto poético (poetischer Gegenstand) de J. Vogl (2003). De similar modo se pronuncia Pardo (2011: 114-115).

9 A propósito del título de este trabajo, pero ya de lleno entrando en los estudios sobre cine de Deleuze, considerando el cine como un objeto de experimentación que revela la naturaleza del movimiento y del tiempo, ver P. Marrati (2003).
} 
sentido, para Deleuze, el tiempo que expone aquella experiencia hace que el sujeto pensante experimente una fisura por la que se expresa que la actividad del pensamiento es la de un otro en él: es la no-coincidencia consigo la experiencia de un otro en él. Dicho de otro modo, es el pensamiento bajo la forma del tiempo el que experimenta la diferencia, pero esto es justamente lo que bajo la ley de la identidad en el concepto $(A=A)$, que rige el proceder de la representación, el sujeto pensante no puede representar en tanto en cuanto la forma vacía del tiempo introducida en aquella ley rompe con aquel principio (2012: 101). En unas pocas palabras, para Deleuze la introducción de aquella forma quiebra el primado del principio de identidad cuestionando el estatuto del sujeto. Entonces, ¿quién piensa en el pensamiento? Deleuze, al enunciar "yo es un otro", que en esto sigue a Kant, ${ }^{10}$ está considerando que es la forma vacía del tiempo la que se ha tornado determinante para la relación entre pensamiento y existencia. Es bajo aquella forma que el pensamiento se revela como la actividad de un otro; es bajo aquella forma del tiempo que aprendemos qué es la existencia, su pasividad, su carácter contemplativo que se expresa en tanto que actividad sintética. En este sentido, hay un paso del tiempo qua lapso de tiempo que hace que el pensamiento no coincida consigo mismo (dicho en clave psico-lógica, se trataría de una bio-grafía). ${ }^{11}$ Pues bien, después de Kant, para Deleuze, es la relación entre existencia y pensamiento la que ha experimentado una revolución que atañe a lo que la determina en cuanto tal al introducirse la forma del tiempo en ella: la forma pura y vacía del tiempo. Como dirá Deleuze,

[d]e un extremo al otro, el Yo [Je] está como atravesado por una fisura: está fisurado por la forma pura y vacía del tiempo. Bajo esta forma, es el correlato del yo [moi] pasivo aparecido en el tiempo. Una falla o una fisura en el Yo [Je], una pasividad en el yo [moi], he aquí lo que significa el tiempo; y la correlación entre el yo [moi] pasivo y el Yo [Je] fisurado constituye el

10 El "yo es un otro" es una de las cuatro fórmulas poéticas propuesta por Deleuze para resumir su lectura de Kant. Ver Deleuze (1996: 44-45). Ver también, la variación que experimenta este enunciado si perder su propio continuo en ¿Qué es la filosofía?, precisamente en la relación que establece Deleuze entre arte y filosofía, (2009: 212).

11 "De modo que la espontaneidad de la cual tenga conciencia en el Yo pienso no puede ser comprendida como el atributo de un ser sustancial y espontáneo, sino solamente como la afección de un yo pasivo (moi passif) que siente que su propio pensamiento, su propia inteligencia, aquello por lo que él dice yo $(J E)$, se ejerce en él y sobre él, no por él” (2012: 141-142 $(116))$. 
descubrimiento de lo trascendental o el elemento de la revolución copernicana (2012: 142).

Es bajo el orden del tiempo, el de "la cesura, y el antes y el después que ordena de una vez por todas" (Deleuze, 2012: 146), que es la expresión simbólica de aquella forma, que se expone lo que piensa en tanto se diferencia del sujeto pensante. Es decir, bajo la forma vacía del tiempo, por la fisura en el yo [Je] lo que se expresa es un otro. $\mathrm{O}$, como dirá Deleuze, ya desde Lógica del sentido a partir de la obra de Joe Bousquet, "mi herida existía antes que yo, he nacido para encarnarla" (Serie XXI). Esta revolución, para Deleuze, llevada a sus últimas consecuencias por Hölderlin, ${ }^{12}$ expresa que la forma vacía del tiempo, su estricta formalidad, está ahí para un "excesivo informal (Unförmliche)" al que cada vez se vuelve en el retorno de lo que no puede representar el sujeto pensante (2012: 149). Dicho de otro modo, la forma vacía del tiempo expresa que la actividad del pensamiento es la de un otro en él y la diferencia le es constitutiva en tanto él es en el tiempo.

Pues bien, si la cesura es el punto de nacimiento de la fisura del sujeto (del yo pensante), en lo que vuelve con ella, las Ideas que se desprenden de los imperativos, y los imperativos son los de un inconsciente, tiene que considerarse una multiplicidad. Dicho de otro modo, lo que puede llevarnos a concebir que lo que opera efectivamente en el tiempo es la defundamentación universal, en la medida en que aquel excesivo informal es lo que ha buscado elaborar Deleuze bajo la noción de multiplicidad (Zourabichvili, 2007: 66-70), tiene que considerarse bajo la experiencia de una cesura. Lo que vuelve bajo aquella forma del tiempo implica la no-coincidencia entre pensamiento y existencia. Podríamos decir, tenemos que considerar una suerte de defondamiento del inconsciente para considerar que lo que piensa no es una sustancia pensante. $\mathrm{O}$, en el decir de Lógica de sentido, hay que sustraerle todo atisbo de telos a lo que piensa; los imperativos son los de un inconsciente que se compone de emisiones de singularidades, pre-individuales y pre-personales, que se distribuyen nomádicamente: el inconsciente no puede considerarse constituido a priori (estaría más allá del

12 Deleuze remite a las "notas sobre Edipo" y a "las notas sobre Antígona”. En la traducción al español, por F. Martínez Marzoa (2014: 146-156 y 157-166). Desarrollar esto está más allá de los límites de este trabajo. 
teatro psicoanalítico) en tanto en cuanto el único a priori es el de la forma vacía del tiempo. Es en este sentido que, citamos a Deleuze,

[L]a ontología es la jugada de dados: «caos-cosmos» [chaosmos] de donde surge el cosmos. Si los imperativos del Ser [los de un inconsciente inasemejable a forma humana alguna, incluso si se le considera por analogía (agregado nuestro)] tienen una relación con el Yo [Je], la tienen con un Yo fisurado, cuya fisura desplazan y reconstituyen cada vez según el orden del tiempo" (2012: 301).

Es decir, en cuanto que vuelve aquello impensable a expresarse bajo la forma vacía del tiempo, el pensamiento que experimenta el límite de sí se extravía en aquello que le demanda pensar: un caos-cosmos (o un cuerpo sin órganos, para decirlo con Mil mesetas). Si la experiencia del pensamiento que está considerando Deleuze es la de la relación entre la diferencia y el tiempo, lo que expresa la relación entre el caos-cosmos y las potencias de lo falso de aquella relación es que ella se experimenta como retorno, y en esta última relación bajo la noción de repetición (répétition). Y para Deleuze no puede sino bajo una noción de répétition considerarse la diferencia: el término répétition en francés puede también traducirse por ensayo. ${ }^{13}$ Ahora bien, permítasenos un juego de palabras, si un ensayo (Versuch) expresa un experimento, también tenemos que intentar considerar que aquella relación entre el caos-cosmos y las potencias de lo falso la presenta ejemplarmente la relación entre arte y pensamiento.

\section{El arte de la caverna}

Antes de proponer una aproximación a la relación entre arte y pensamiento, es deseable volver a considerar cómo opera el platonismo para concebir la relación entre las potencias de lo falso y el caos-cosmos. Pues, como bien sabía Nietzsche, aquella operación está fundada en una imagen moral del mundo (y no

13 Recordemos que Michel Foucault (1995) propuso una lectura de Diferencia y repetición inspirado en una suerte de teatrología de la misma. Por otra parte, Deleuze llama a la voluntad de potencia: teatro de toda metamorfosis (2012: 360) 
tenemos que olvidar la impresión estética que está implicada en aquella imagen). Pero para esto hay que considerar el vínculo entre la dialéctica y el mito. En la lectura de Deleuze, Platón va elaborar un método cuyo leitmotiv no es distinguir a las especies de un género sino más bien, "dividir una especie confusa en linajes puros, o de seleccionar un linaje puro de un material que no lo es" (Deleuze, 2012: 106). Este método de división, de lo puro y lo impuro, de lo bueno y lo malo, de lo auténtico y lo inauténtico, halla en el mito su piedra de toque; es que en cuanto se descubre que es con aquel método que opera la dialéctica se revela que ella necesita de un fundamento indecidible. Citamos,

[P] ues, si bien es cierto que el mito y la dialéctica son dos fuerzas distintas en el platonismo en general, esta distinción deja de valer en el momento en que la dialéctica descubre en la división su verdadero método. La división supera la dualidad e integra el mito en la dialéctica, hace del mito un elemento de la dialéctica misma. La estructura del mito aparece claramente en Platón: es el círculo, con sus dos funciones dinámicas, girar y volver, distribuir o repartir; la distribución de las partes pertenece a la rueda que gira, así como la metempsicosis al eterno retorno (Deleuze, 2012: 109).

¿Qué es lo que instituye un mito? Un fundamento. Esto es lo que no puede estar fundando racionalmente, como decíamos al principio, esto es el fundamento infundado del platonismo: el mito es lo indecidible, la otra cara de la dialéctica. Para Deleuze, distinguir entre auténticas copias y falsas copias, expulsar los simulacros en tanto en cuanto se asemejan a la copia de una copia, tiene como fin jerarquizar las apariencias acorde a lo que es verdadero en el platonismo: una imagen o mito moral y político que subyace a la dialéctica. En este sentido, aquellas copias de copias que han perdido toda semejanza con el original en cuanto problematizan aquella distinción son necesarias de expulsar; célebre en este sentido es la expulsión de casi todos los poetas de la República de Platón, pues un simulacro es lo que se hace indistinguible de una copia (lo cual significa que los simulacros pueden derrocar los mitos que busca instaurar Platón para su República). Pues bien, citamos a Deleuze, 
[C]onforme a la más antigua tradición, el mito circular es, en efecto, el relato-repetición de una fundación [por ejemplo, en el Político bajo la forma del Dios-pastor (agregado nuestro)]. La división lo exige como el fundamento capaz de establecer la diferencia; a la inversa, exige la división como el estado de la diferencia en lo que debe ser fundado (2012: 109).

Si Deleuze buscará proponer un concepto de la diferencia en sí misma, que no opere bajo una concepción mítica de ella, es decir, bajo el relato-repetición de una fundación, también hará de la repetición una noción esencial para la elaboración de aquel concepto. La diferencia, más allá de la mediación de la identidad conceptual, es la que hay que afirmar en la repetición de ella. Pero, entonces, ¿hay acaso un círculo del cual Deleuze no ha podido escapar? ¿resta la lógica de aquella estructura mítica? O bien, ¿no era la distinción entre mito y dialéctica la que se exponía como problemática? Pues bien, si la diferencia retorna en una repetición, ella no puede retornar sin hacer de la diferencia el efecto de una répétition. Pero ¿quién es el que la instaura?, ¿qué es lo que instaura? Como dirá Deleuze, citamos,

Platón oponía el eterno retorno al caos, como si el caos fuera un estado contradictorio, que debiera recibir desde afuera un orden o una ley, semejante a la operación del Demiurgo tratando de moldear la materia rebelde. [Y] remitía al sofista a la contradicción, a ese estado supuesto del caos, es decir, a la más baja potencia, al último grado de participación. (...) [Pero] en verdad, la enésima potencia no pasa por dos, tres, cuatro, sino que se afirma inmediatamente para constituir lo más alto: se afirma del caos mismo; y, como dice Nietzsche, el caos [caos-cosmos (agregado nuestro)] y el eterno retorno no son dos cosas distintas (2012: 116).

En cuanto Deleuze considera que una enésima potencia no pasa por distintos estadios sino más bien están plegadas o implicadas las diferencias en intensidad en ella, la naturaleza de la diferencia es la que se expresa en el eterno retorno. Dicho de otro modo, para Deleuze el pensamiento del eterno retorno opera como un transporte en tanto en cuanto afirma cada vez lo que se expresa en él: 
el movimiento de la diferencia. Es en este sentido que puede decirse, como dice Deleuze, que aquel pensamiento es necesario para constituir lo más alto al mismo tiempo que se expresa como inmanente a la experiencia de aquel. Para Deleuze, lo que cada vez vuelve en el tiempo una vez resquebrajada la representación es la naturaleza de la diferencia; esto es, en un encuentro con lo que la hace sentir y pensar vuelve a experimentarse una enésima potencia. El resultado que arrojen los dados implica la diferencia, pero es lo impredecible el resultado: no podemos anticipar lo que va a expresar lo inconsciente. ${ }^{14}$ En términos bergsonianos, lo que está plegado intensivamente es la memoria, pero ella no vuelve sino como olvido. Entonces, ¿podríamos intentar considerar una mezcla de autores o, como le gusta decir a Deleuze en Diferencia y repetición, un collage (2012: 18)? Pero, para que se sostenga el cuadro es necesario tornarlo verosímil. Pues bien, habríamos de decir que en Deleuze el cruce que tenemos que intentar concebir para aproximarnos a aquella relación entre las potencias de lo falso y el caos-cosmos, y con ello a la relación entre arte y pensamiento, es entre la noción de devenir nietzscheano y la noción de memoria bergsoniana. Brevemente, una memoria que para Deleuze, y para Bergson, sale de la esfera de lo humano extendiéndose intensivamente en la evolución no-humana (2012: 320). ${ }^{15}$ Un devenir para Deleuze, pero en los términos de la Ciencia jovial $\$ 54$ de Nietzsche, en el que lo viviente se afirma en tanto apariencia (Schein), en la que

[L]a más excelsa consecuencia e interrelación de todos los conocimientos es y seguirá siendo, tal vez, el medio supremo para mantener de pie la universalidad de las ensońaciones y el pleno entendimiento de todos estos soñadores entre sí, y también junto a ello, la duración del sueño.

\footnotetext{
14 Para David Lapoujade, en su estudio en torno a Deleuze, "Diferencia y repetición y Lógica del sentido están bajo el signo de ese sin fondo y de aquello que lo puebla, singularidades preindividuales e impersonales, intensidades, multiplicidades, diferencias libres o nómadas. Toda la "filosofía de la diferencia" sale de ahî" (2016: 34).

15 Como dirá P. Marrati, "Bergson hace de la duración la apertura del tiempo como cambio, apertura del universo o del ser. Bergson llama a menudo a esta dimensión el Todo. Pero, insiste en ello Deleuze, es necesario no equivocarse: el Todo no es un conjunto cerrado; él mismo es lo Abierto, dimensión de un ser-tiempo que cambia y así dura y produce lo nuevo. Si los movimientos son cualitativos y heterogéneos es porque participan en el Todo del universo. Expresa un cambio en el Todo" (2003: 24).
} 
Pues bien, para Deleuze, el devenir vuelve como un olvido en el que se expresa la duración de un sueño que puede considerarse como la repetición (répétition) de una memoria de caos-cosmos. Podríamos decir, que con Bergson y Nietzsche, siguiendo la lectura de Deleuze, es el olvido de la memoria lo que un animal-simbólico experimenta, lo que no puede repetir sino olvidando. En este sentido, un encuentro con un signo y/o una imagen abre la experiencia de una multiplicidad que implica una memoria y un devenir en tanto Olvido en cuanto se expresan distintos umbrales que desplegándose van presentando lo inhumano de lo humano, lo otro de lo humano. O como dirá Deleuze, a propósito de Proust, "lo virtual no se opone a lo real, sino tan solo a lo actual. Lo virtual posee una realidad plena en tanto es virtual [cursiva de G.D]" (2012: 314-315). En este punto, considerando lo dicho, si el acontecimiento equivale a un devenir-otro y él se experimenta en una obra de arte al devenir ella experiencia, ¿`cómo encontrar lo virtual? Que un acontecimiento define la experiencia del pensamiento en tanto trae de vuelta una enésima potencia, tendría que llevarnos a considerar, siguiendo a Nietzsche, una incorporación (Einverleibung) de aquel. ${ }^{16}$ Si lo otro en el pensamiento se experimenta como una multiplicidad que se compone de relaciones dispares y de diferencias en intensidad que expresaran la naturaleza de lo que en él piensa: un caos-cosmos o, en los términos de Lógica del sentido, "un mundo hormigueante" (serie $X V$ ), también hay que concebir que aquella experiencia puede devenir una suerte de novela: la de un mundo como novela: una en que se expresa el tiempo fuera de quicio (hay que considerar que la forma del tiempo se ha introducido en aquella o bien, que con aquella introducción comienza una novela, pero no podemos saber en principio en cuál página. Un caso ejemplar para Deleuze es el Ulises de Joyce, y las referencias a Hamlet en el Ulises son sin duda claves). Dirá Deleuze respecto a esta novela que, "[s]e confunde con la gran obra, que mantiene todas las series complicadas, que afirma y complica todas las series simultáneas" (2012: 192). Pues, si en esta obra se halla implicado lo que (se) diferencia (en) ella (la parte virtual de ella): un caos-cosmos, lo que le interesa a Deleuze de ello es el desplazamiento del sentido o del sin-sentido que va dispersando las historias en la medida en que retorna un movimiento aleatorio que va propagando y constituyendo la gran obra, ${ }^{17}$ pues en aquel mundo se experimentaría un extravío o un laberinto que es propio al desplazamiento de

16 Nietzsche, F.: La ciencia jovial, trad. Jara, J., Caracas, Monte Ávila Editores Latinoamérica, 1999, \$110. “¿Hasta qué punto tolera la verdad hacerse cuerpo [die Einverleibung: la incorporación]? -Esa es la pregunta, ése es el experimento”, Ibidem.

17 Podría considerarse lo que dice Deleuze respecto a la novela Cosmos de Gombrowicz (2012: 191), y singularmente lo que ya en el prólogo se expresa en tanto que este "esboza una teoría de las series inconexas, de su resonancia y del caos", (2012: 191). 
lo que va tomando consistencia por azar, esto es, el caos-cosmos. En Deleuze, si estas historias son constitutivamente divergentes en tanto que aleatoria la comunicación entre ellas, es porque, en términos del filósofo francés, "el horizonte de convergencia está en un caos, desplazado siempre en ese caos. Este caos mismo es lo más positivo, al propio tiempo que la divergencia es objeto de afirmación" (2012: 192). En este sentido, retorna una relación disyuntiva: divergencias que expresan simultáneamente aquella gran obra como constitutivas de ella, lo cual expone que el mundo en tanto novela se presenta como un caos-cosmos. Como diría Deleuze con Borges, ${ }^{18}$

Fang, digamos, tiene un secreto; un desconocido llama a su puerta; Fang resuelve matarlo. Naturalmente, hay varios desenlaces posibles: Fang puede matar al intruso, el intruso, puede matar a Fang, ambos pueden salvarse, ambos pueden morir, etc. Todos los desenlaces ocurren; cada uno es el punto de partida de otras bifurcaciones" (2002: 142). ${ }^{19}$

Que en Deleuze cada historia que diverge no sea "un punto de vista diferente sobre una misma historia, a la manera de los puntos de vista sobre la ciudad según Leibniz", "[sino] historias completamente distintas que se desarrollan simultáneamente” (2012: 191), expresa que una enésima potencia en su más alta expresión presenta un mundo como constitutivamente divergente ${ }^{20}$. Pues bien, lo que vuelve a instaurar la diferencia, aquello que hace de la repetición (répétition) un acto de creación, ${ }^{21}$ puede llegar a experimentarse como una experiencia del pensamiento. En el caso de la gran obra puede tratarse de la experiencia de una novela, pero una que se torna interminable, inacabable, sin comienzo ni fin, encontrándonos en ella justo en el medio de una disyunción: "[e]sa trama de

18 Pues véase también en torno al juego de la lotería y el azar, Lógica del sentido, serie X. Y si bien la obra literaria principal en Lógica de sentido es la de Lewis Carroll el papel de Jorge Luis Borges, y principalmente, de Ficciones, no deja de ser relevante.

19 En Lógica del sentido este fragmento se expresa en la serie XVI.

20 Borges dirá en El jardín de senderos que se bifurcan, "[c] asi en el acto comprendí, el jardín de los senderos que se bifurcan era la novela caótica. (...). En todas las ficciones, cada vez que un hombre se enfrenta con diversas alternativas, opta por una y elimina las otras; en la del casi inextricable Ts'ui Pên, opta -simultáneamente- por todas. Crea diversos porvenires, diversos tiempos que proliferan y se bifurcan" (2002: 141-142).

21 Llevándola a un extremo, al modo de "Pierre Minard, autor del Quijote" en Borges, ver, (2002: 51-66) 
tiempos que se aproximan, se bifurcan, se cortan o que secularmente se ignoran, abarca todas las posibilidades" (Borges, 2002: 145). ${ }^{22}$

Un caos-cosmos expresa la naturaleza azarosa de un pensamiento que hallándose en accidentes, afecciones, sucesos, se experimenta conmocionado por lo que en él piensa. Lo cual implica concebir que aquella experiencia del pensamiento involuntariamente se encuentra con el acontecimiento, como si se encontrará por un golpe de dados con él; es un acontecimiento el que encuentra aquella experiencia alterándola (de ahí la naturaleza involuntaria o pasiva que se expresa). Para Deleuze, el pensamiento experimenta un extravío, se extravía en un laberinto que no tiene comienzo ni fin para encontrarse en otro desvío; desvíos de desvíos hasta encontrarse con aquel secreto que tiene Fang según Borges y que no implica sino varios desenlaces posibles. Pero si consideramos que aquella experiencia puede volver a repetirse, es la repetición (répétition) de ella la que la expresa las potencias de lo falso en tanto en cuanto lo que se ensaya puede concebirse como un acto de creación que expone lo que afirman aquellas potencias. ${ }^{23}$ Pues bien: lo que no se puede saber es lo que de aquel ensayo se instauraría de un enfrentamiento contra el caos: lo que es creado nace del olvido (de la memoria). La experiencia del pensamiento adviene en un encuentro que no puede sino sentirse, considerando que el signo de una intensidad es lo que se siente en tanto aquel expone la diferencia. En este sentido, en Deleuze un devenir se presenta como la verdad de lo falso en cuanto se expresa como potencia de lo falso de la vida. En el decir de la Ciencia jovial $\$ 54$ de Nietzsche, de la apariencia (Schein). En unas pocas palabras, no hay sino potencia de lo falso, o sea, la verdad es de lo falso en tanto ella vuelve a dar la experiencia de un caos-cosmos. Como dice Deleuze en Nietzsche y la filosofía, "la actividad de la vida es como una potencia de lo falso, engañar, disimular, deslumbrar, seducir. Pero para que se efectúe, esta potencia de lo falso debe ser seleccionada, redoblada o repetida, es decir, elevada a una más alta potencia” (2002: 145). O como diría H. Michaux,

\footnotetext{
22 "-Precisamente- dijo Albert-, El jardín de senderos que se bifurcan es una enorme adivinanza, o parábola, cuya tema es el tiempo; esa causa recóndita le prohíbe la mención de su nombre" (Borges, 2002: 144).

23 "La potencia de lo falso debe ser llevado hasta una voluntad de engañar, voluntad artística única capaz de rivalizar con el ideal ascético y de oponerse con éxito a este ideal. Precisamente el arte inventa mentiras que elevan lo falso a esta mayor potencia afirmativa, hace de la voluntad de engañar algo que se afirma en la potencia de lo falso" (Deleuze, 2002: 145).
} 
Las extensiones más considerables, las menos parecidas al hombre son las que entonces más le convienen. De nuevo todo es posible. Lo "sin forma", el "Todo" puede ocurrir. Si permanecemos en el ensueño. El activo ensueño. El ensueño que siempre hay que volver a empezar (2005: 212).

La experiencia del pensamiento la despliega una enésima potencia que en la medida en que se presenta como multiplicidad expresa para Deleuze "la diferencia infinitamente desdoblada que resuena al infinito" (2012: 333-334). Pues bien, si en este trabajo intentamos decir que la natura naturans es otro nombre para las potencias de lo falso, ${ }^{24}$ es justamente esto lo que no podría volver a tornarse sentible $y$ pensable sin experimentar la improductividad de aquella naturaleza en una exposición que la exprese, esto es, en una obra de arte. Como dirá Deleuze, "en condiciones tales que lo falso se convierte en el modo de exploración de lo verdadero, en el espacio propio de sus disfraces esenciales o de su desplazamiento fundamental: el pseudos aquí devino el pathos de lo Verdadero" (2012: 170).

En otras palabras, la gran obra es una exposición de lo que se expresa bajo la forma vacía del tiempo, ahora considerando que la diferencia la presenta un movimiento que la gran obra revela como el de un caos-cosmos. Para Deleuze, en cuanto la gran obra vuelve a dar un caos-cosmos está ella presentando lo que bajo golpes de azar el pensamiento introducido en la forma vacía del tiempo experimenta: una propagación del sentido o del sin-sentido que va componiendo la diferencia entre devenir $y$ memoria. Bajo esta perspectiva, como dirá Deleuze en El Pliegue, el pensamiento es para el mundo (1989: 39) y lo que la gran obra expresa del mundo es que él se expresa como un caos-cosmos. Pues bien, la relación entre arte y pensamiento plantea de otro modo la relación entre el caoscosmos y las potencias de lo falso en la medida en que aquella relación es la que revela a esta. Aquella relación expresa que la naturaleza de un acontecimiento en el que se expone un mundo que nos es inmanente y que experimentamos como

24 J.L. Pardo (2011) ha aclarado notablemente esta cuestión a partir de los cruces de lectura que propone Deleuze en su obra, en particular, entre Bergson, Nietzsche, Spinoza (pero Pardo no se limita a estos autores filósofos). Respecto a esto último, en el cruce entre Bergson y Spinoza en Deleuze, ver (2011: 51-70 y las nota de la página 53). 
inmanente implica un acto de creación; ${ }^{25}$ y es dicha inmanencia la que Deleuze considera bajo la figura de un volver-a-venir, de un eterno retorno. ${ }^{26}$ Ahora bien, lo que se va trazando bajo aquella relación se presenta como un posible: "de nuevo todo es posible" como decía Michaux. Que la actividad del pensamiento experimente como posible un mundo-otro, un devenir-otro, en la medida en que ha hecho la experiencia de la más alta potencia, quiere decir que ha hecho de un encuentro con una obra de arte un ensayo en y con el cual se expresa que aquella relación entre el caos-cosmos y las potencias de lo falso presenta un acontecimiento que bajo el pensamiento del eterno retorno se expone como el de un puro por-venir (Deleuze, 2012: 148-149).

\section{Del círculo y la línea. A modo de conclusión}

\section{Yo sé de un laberinto griego que es una linea única, recta. \\ Jorge Luis Borges, La muerte y la brújula.}

Si en Platón la otra cara de la dialéctica es el mito en cuanto se halla en él el fundamento que permite fundar el movimiento del método de la división, en Deleuze la otra cara de la experiencia del pensamiento son las artes en cuanto ellas son objetos de un encuentro que expone la más alta expresión de las potencias de lo falso que es la vida. En el decir de Nietzsche y la filosofía, "apariencia [Schein (agregado nuestro)] ya no significa la negación de lo real en este mundo (...). Verdad es apariencia. Verdad significa efectuación de la potencia, elevación a la más alta potencia" (2002: 145). Un encuentro con aquellas potencias, con una enésima potencia que ha devenido una obra de arte, volvería hacer de una experiencia del pensamiento un ensayo de lo real en ella. Esto es, volvería a experimentarse en ella la heterogénesis de un caos-cosmos en tanto la potencia

25 En torno al acto de creación, ver (Deleuze, 2007: 281-289).

26 La articulación que implica el abandono del dominio de la representación, la ruptura del principio de identidad y la expresión del plano de inmanencia, a partir del papel de Nietzsche y Spinoza en Deleuze, la elabora P. Mengue (2008) en la presentación que realiza del pensamiento del filósofo francés. Notable nos parece al respecto la cuarta parte titulada Del deseo y los flujos en tanto revela a partir del contraste con el psicoanálisis lacaniano la noción de deseo que expresa el pensamiento de Deleuze, clave, por como presenta Mengue la dificultad que en dicha noción habita, es decir, para comprender lo que implica aquella articulación que en principio mencionamos. 
de lo falso expresa una vida que toma consistencia como experiencia; hace la diferencia una obra de arte en la medida en que se experimenta en ella aquella intensidad que hace pensar el pensamiento. En este sentido, para Deleuze lo que ensaya aquella relación entre arte y pensamiento es un movimiento en el que lo que se ha tornado inmanente es un mundo. En los términos de Diferencia y repetición,

No es ya el esfuerzo platónico por oponer el cosmos al caos, como si el Círculo fuese la huella de la Idea trascendente capaz de imponer su semejanza a una materia rebelde. Es incluso todo lo contrario, la identidad inmanente del caos con el cosmos, el ser en el eterno retorno, un círculo de otro modo tortuoso (2012: 199).

Pues bien, es el retorno en tanto que afirmación de la diferencia en sí misma el que estaría implicado en el hacer del caos-cosmos un cosmos. De ahí que "[1]a afirmación es el producto de un pensamiento que supone una vida activa como su condición y su concomitancia (Deleuze, 2002: 144). En otros términos, Deleuze al decir que la ontología es "[l]a jugada de dados: caos-cosmos" está considerando que la relación entre las potencias de lo falso y el caos-cosmos es inmanente, es decir, el tiempo que vuelve a dar una obra de arte es el de una experiencia de la inmanencia en tanto el pensamiento es para el mundo. En este sentido, está en juego un signo de equivalencia, pues la lectura deleuzeana de Nietzsche considera que, citamos, "[p]ara Nietzsche, nosotros los artistas = nosotros los buscadores de conocimiento o de verdad = nosotros los inventores de nuevas posibilidades de vida" (2002: 145). Labor crítica y clínica, también, en aquella equivalencia, si consideramos lo que dirá Deleuze en La imagen-tiempo, citamos en extenso,

El afecto como evaluación inmanente en lugar del juicio como valor trascendente: "yo amo o yo detesto» en lugar de "yo juzgo». Nietzsche, que sustituia el juicio por el afecto, prevenía a sus lectores: más allá del bien y del mal no significa al menos "más allá de lo bueno y de lo malo" [cursivas nuestras]. Lo malo es la vida agotada, degenerada, que es mucho más terrible, capaz de propagarse. Pero lo bueno es la vida naciente, ascendente, aquella que sabe transformarse, metamorfosearse según las fuerzas que encuentra, y que compone con ellas una potencia cada vez más grande, aumentando cada vez más la potencia de vivir y abriendo siempre nuevas "posibilidades». Es cierto que no hay más 
verdad en una que en otra; no hay sino devenir, y el devenir es la potencia de lo falso de la vida, la voluntad de potencia [cursivas nuestras] (2015: 191).

La identidad inmanente del caos con el cosmos, el caos-cosmos, la expresa la relación con las potencias de lo falso en la medida en que ella expone que aquella identidad es la de un devenir-otro. Ahora bien, que una experiencia del pensamiento la presente una obra de arte en cuanto genera un encuentro con lo real de aquella, implica considerar que una obra de arte expresa el carácter singular de una experiencia. Si en Deleuze la gran obra es un mundo que se caracteriza por series divergentes, por caminos que se bifurcan desde el comienzo, por un horizonte que halla su convergencia en un caos, en el que una experiencia se experimenta en un extravío constitutivo a ella, también las obras que pueblan aquel mundo hay que considerarlas como distintas expresiones que abren $y$ crean un mundo. Cada obra traería una historia distinta de aquel mundo, una historia que diverge de otra historia y otra historia. Quizás esto pueda decirse en los términos de la Ciencia jovial $\$ 322$ de Nietzsche, pues “quien mira dentro de sí como en un inmenso espacio sideral y lleva vías lácteas dentro de sí, sabe también cuán irregulares son todas las vías lácteas; ellas conducen hasta el caos y el laberinto de la existencia”. Este símil que podría proponerse para pensar en el devenir de un caos-cosmos, habríamos también que intentar concebirlo como una alegoría, porque si ella "descubre la naturaleza y la historia según el orden del tiempo, convierte la naturaleza en historia y transforma la historia en naturaleza, en un mundo que ya no tiene centro" (Deleuze, 1989: 161 [cursivas nuestras]), esta conversión y transformación en el orden del tiempo, $y$ el tiempo está fuera de quicio, s experimentaría como una experiencia de las potencias de lo falso. Y, para Deleuze, expresan estas potencias un devenir en tanto son experimentadas en una obra de arte que ha devenido experiencia. En este sentido, quizás en un encuentro con ella hallemos aquel pathos de lo verdadero. Es decir, la potencia de lo falso que es la vida. En un mundo que ya no tiene centro, en esta ficción de lo real que expresa que la verdad es apariencia (Schein), se presenta un caos-cosmos del cual tal vez nazca un cosmos. O como diría en Clio C. Péguy, e intentamos considerar esta obra como una en la que la relación entre arte y pensamiento expresa un acontecimiento, 
Vea en su memoria. Y vea si no hay períodos y épocas, planicies y puntos de crisis. (...). Verá usted, ve que el flujo, que el acontecimiento de lo real no es (allí) homogéneo en absoluto, que no es sólo un tiempo y que de ningún modo parece sólo un tiempo, (...) no es sólo una pura materia matemática, aritmética, teórica, histórica; ve usted que hay duraciones reales, realmente duraciones de pueblo, realmente quizá una duración del mundo mismo" (2009: 283-282-283).

Para concluir, volvamos a preguntar por la relación entre arte y pensamiento, considerando que la enésima potencia de lo falso vuelve a dar una experiencia del caos-cosmos. Pues bien, si concebimos que aquella relación en ¿¿Qué es la filosofía? (2009) la expresa el acontecimiento que expone el silencio interior de Kandinsky o el concepto no-conceptual de Klee (2009: 220), tendremos que considerar lo que Deleuze y Guattari llaman en Mil Mesetas, la falta de un pueblo (2010: 349) o en ¿Qué es la filosofía? "la sombra del "pueblo venidero (peuple à venir)» (2009: 220)". Pues aquella relación implica una pregunta por la naturaleza de lo político, por un pueblo ${ }^{27}$. Para Deleuze, en lo que tiene de inanticipable aquella relación entre el caos-cosmos y las potencias de falso, se halla sentida y pensada aquella relación entre arte y pensamiento en la medida en que la exposición de una obra de arte se ha tornado expresión de un pueblo que falta. En este sentido, en la experiencia de una obra de arte se experimentaría aquello que en Nietzsche se llama apariencia (Schein) o aquello que Michaux llama el activo ensueño (l'active rêverie), conceptos que están relacionados con "un todo", con lo "sin-forma", o con "la universalidad de las ensońaciones" o "el pleno entendimiento de los y las sońadoras". Dicho de otro modo, lo que hay que atender en una aproximación a la heterogénesis de las potencias de lo falso es el movimiento que está Deleuze considerando en la relación entre arte y pensamiento en tanto aquel implica una pregunta por la naturaleza de lo político: por la falta de un pueblo. Pero para desarrollar esto sería necesario otro trabajo.

27 Dirán Deleuze y Guattari en Mil Mesetas, "No son los artistas populares o populistas, es Mallarmé el que puede decir que el Libro tiene necesidad de pueblo, y Kafka, que la literatura es el quehacer del pueblo, y Klee, que el pueblo es lo esencial, y que, sin embargo, falta. (2010: 349). 


\section{Bibliografía}

Borges, J. L. (2012). Ficciones. Buenos Aires: EMECÉ.

Deleuze, G. (2004). Le bergsonisme. Paris: Quadrige /PUF.

- (1995). Proust y los signos. Trad. Monge, Francisco, Barcelona: Editorial Anagrama.

- (2002). Nietzsche y la filosofía. trad. Artal, Carmen. Barcelona: Editorial Anagrama, Barcelona.

- (2012). Diferencia y Repetición. trad. Delpy, María Silvia y Beccacece, Hugo. Buenos Aires, Amorrortu.

- (2011). Lógica del sentido. trad. (texto) Morey, Miguel y (apéndice) Molina, Víctor. Madrid: Paidós.

Deleuze, G. y Guattari, F. (2010). Mil mesetas. Capitalismo y esquizofrenia. Trad. Vásquez Pérez, José con colaboración de Larraceleta, Umbelina. Valencia: Pre-Textos.

Deleuze, G. (2015). La imagen-tiempo. Trad. Agoff, Irene. Barcelona: Paidós.

- (1996). "Sobre cuatro fórmulas poéticas que podrían resumir la filosofía kantiana”. En: Critica y Clínica. trad. Kauf, Thomas. Barcelona: Editorial Anagrama, pp. 44-55.

- (1989). El pliegue. Leibniz y el Barroco. Trad. Vásquez Pérez, José y Larraceleta, Umbelina Barcelona: Ediciones Paidós.

Deleuze, G. y Guattari, F. (2009). ¿Qué es la filosofía? Trad. Kauf, Thomas. Barcelona: Editorial Anagrama.

Deleuze, G. (2005). La Isla Desierta y otros textos. Textos y entrevistas (1953-1974). Trad. Pardo, José Luis. Valencia: Pre-Textos.

De Beistegu, M. (2004). "Onto-hetero-genesis: thinking Difference with Deleuze”. En: Truth and genesis. Philosophy as Differential Ontology. Bloomington, Indiana University Press, pp. 187-334.

- (2012). "The Deleuzian reversal of Platonism". En: Ed. Smith, D. W. y Somers-Hall, H. The Cambridge Companion to Deleuze. Cambridge: Cambridge University Press, pp. 55-81.

Foucault, M. y Deleuze, G. (1995). Theatrum Philosophicum seguido de Repetición y diferencia. Trad. Monge, Francisco. Barcelona: Anagrama.

HöLderLin, F. (2014). Ensayos. Trad. Martínez Marzoa, F. Madrid: Ediciones Hiperión.

Lapoujade, D. (2016). Deleuze, los movimientos aberrantes. Trad. Ires, P. Buenos Aires: Cactus. 
Marrati, P. (2003). Gilles Deleuze. Cine y filosofía. Trad. Bernini, E. Buenos Aires: Nueva Visión.

Mengue, P. (2008). Deleuze o el sistema de lo múltiple. Trad. Fava, J.M y Tixi, L. Buenos Aires: Las Cuarenta.

Michaux, H. (2005). Antología poética. 1927-1986 (Bilingüe). Trad. y selección Mattoni, Silvio. Buenos Aires: Adriana Hidalgo.

NiETzsche, F. (1999). La ciencia jovial. Trad. Jara, José. Caracas: Monte Ávila Editores Latinoamérica.

- (1999). Epistolario. Ed. Muñoz, Jacobo. Madrid: Biblioteca Nueva.

Pardo, J. L. (2011). El cuerpo sin órganos. Presentación de Gilles Deleuze. Madrid: PreTextos.

PÉGuY, C. (2009). Clío. Diálogo entre la historia y el alma pagana. Trad. Fólica, Laura. Buenos Aires: Editorial Cactus.

Ruiz Stull, M. (2013). Tiempo y experiencia. Variaciones en torno a Bergson. Chile: Fondo Cultura Económica.

Sauvagnargues, A. (2009). Deleuze, L'empirisme transcendantal. Paris: Presses Universitaires de France.

Smith, D. W. (2012). "The concept of the Simulacrum. Deleuze and the Overturning of Platonism”. En: Essays on Deleuze. Edinburgh, Edinburgh University Press, pp. 3-26.

VogL, J. (2003). Was ist ein Ereignis? en ZKM. Symposien Gilles Deleuze und die Künste. Wiederholung und Differenz. http://on1.zkm.de/zkm/stories/storyReader\$4048\#eins.

ZourabichVILLI, F. (2007). El vocabulario de Deleuze. Trad. Goldstein, Víctor. Buenos Aires: Editorial Atuel.

Recibido: 4/01/2018

Aceptado: 5/10/2018

Este trabajo se encuentra bajo una licencia de Creative Commons ReconocimientoNoComercial-SinObraDerivada 4.0

\section{c) (i) $(9)$


